\title{
Interview
}

\section{On Social and Organisational Psychology: Interview with Alex Haslam}

\author{
Vlad Glăveanu*a , Alex Haslam ${ }^{b}$
}

[a] London School of Economics, London, United Kingdom. [b] School of Psychology, University of Queensland, St Lucia 4072, Australia.

\begin{abstract}
In this interview Prof. Alex Haslam discusses his past and present work in social and organisational psychology and the multiple ways in which these two fields are inter-connected. He considers the guiding threads within his scientific activity from the famous BBC Prison Study to more recent work on leadership. Covering both theoretical to applied considerations, this interview addresses important questions for psychologists working in organisations and elsewhere in society. It offers a glimpse into the fascinating world of humans as social beings capable of forming groups and sharing identities, of including but also excluding, of both following and leading.
\end{abstract}

Europe's Journal of Psychology, 2012, Vol. 8(3), 321-326, doi:10.5964/ejop.v8i3.494

Received: 2012-07-05. Accepted: 2012-07-11. Published: 2012-08-29.

*Corresponding author at: psy.journal@gmail.com.

This is an open access article distributed under the terms of the Creative Commons Attribution License

(http://creativecommons.org/licenses/by/3.0), which permits unrestricted use, distribution, and reproduction in any medium, provided the original work is properly cited.

Vlad Glăveanu: Professor Haslam, your work in the past decades has made significant contributions to the literature in both social and organisational psychology. You have covered a variety of topics from stress, motivation and leadership to stereotyping, extremism and resistance. What would you say are the common threads within your research, the core questions you have been preoccupied with, and how did your interest in all these different topics evolve?

Alex Haslam: All my work has developed from my original interests in social identity and self-categorization theories, and from my original PhD work which explored the role that social context plays in structuring people's understanding of self. A key point that emerged clearly from this was that the nature of self varies, and varies logically, so that in some contexts people define themselves (and act) as individuals in terms of their personal identity (as "I" and "me") and in other contexts they define themselves (and act) as group members in terms of a social identity (as "us" and "we") that is shared with others, and with whom the self becomes categorically interchangeable. Moreover, the content of social identity also changes lawfully as a function of changes in context - so that "us psychologists" means something different (and dictates different forms of behaviour) when we compare ourselves with physicists rather than footballers.

On the face of it, this is a very simple idea. However, once you really embrace its full implications, you see that they are very radical and, moreover, that they challenge a whole host of assumptions and notions that are pervasive in social and organizational psychology. Is the nature of self fixed? No. Is the true self found in people's individuality? No. Are categorical representations (that accentuate intra-category similarity and inter-category difference) a distortion of reality? Not necessarily. Are these categorical representations central to processes like communication, trust, and leadership? Absolutely. Once such realizations had got hold of me, it was as if I had caught a thread 
that started to unravel the whole jumper of our discipline - but which then allowed me to work with others to try to reknit it in a different form.

Vlad Glăveanu: More generally, how do you think social psychology can advance our understanding of organisational phenomena and, in turn, organisational psychology can add to social psychological theories?

Alex Haslam: I don't think it's possible to have viable models of organizational psychology without a good understanding of social psychology. However, I think this is true for all sub-branches of our discipline, since, as I see it, all psychology is social psychology - for the simple reason that, at core, humans are social animals whose psychology has evolved to support group life and to make it possible. At the same time, the problem with a lot of social psychology is that it isn't very social psychological. For me the great thing about organizational psychology is that its social dimensions are unavoidable. Accordingly, it forces us to deal with the fundamentally social nature of our psychology, and its subject matter throws out the most important challenges for psychology as a whole. So, in addressing the nature of things like leadership, communication, and innovation - indeed to grapple with what it is that makes organizational behaviour possible - we are addressing the biggest and most important questions in the discipline.

Vlad Glăveanu: Perhaps one of the most visible research projects you have coordinated in the past, together with Professor Steve Reicher, is the famous BBC Prison Study (Haslam \& Reicher, 2006; Reicher \& Haslam, 2006). How did you come to do this large-scale project and how did its findings influence your research since then?

Alex Haslam: It's hard to underestimate the impact this had on me - at a number of levels. First, the study opened my eyes to the ways in which our understanding of psychology is constrained by sub-disciplinary and topic boundaries. That is, in the study it clearly wasn't the case that social psychology (e.g., influence, stereotyping) was going on in one corner, organizational psychology (leadership, planning) in another, and clinical psychology (anxiety, depression) in another. Instead, these things were seamlessly interdependent. At the same time, though, the analytical tools provided by social identity theorizing allowed us to integrate across these domains and to see conceptual relationships that we hadn't seen before. In particular, it became apparent that at the same time that social identity is the basis for group processes like influence, communication and leadership, its erosion is a basis for disorganization, stress, and depression. And here the great thing about the study was that it allowed us to see these processes both in the flesh and as they unfolded. Prior to this I hadn't really noticed how much time I (and others) had devoted to studying phenomena that we never

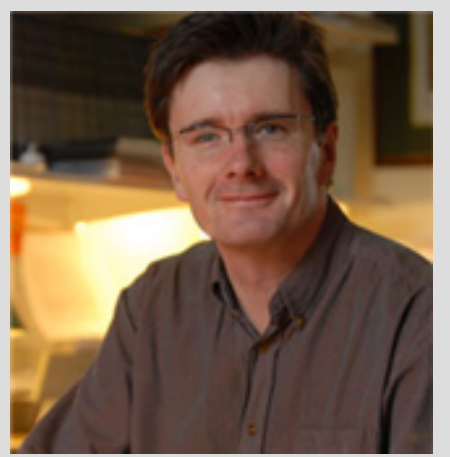

Alex Haslam is Professor of Social and Organizational Psychology and Australian Laureate Fellow at the University of Queensland and a former Commonwealth Scholar at Macquarie University (Sydney) and Jones Scholar at Emory University (Atlanta). He was Associate Editor of the British Journal of Social Psychology from 1999 to 2001 and Chief Editor of the European Journal of Social Psychology from 2001 to 2005. At Queensland he is part of a team of internationally renowned researchers who conduct theory-driven research into a range of core social and organizational topics - including leadership and motivation, stress and health, power and prejudice. His work in this team is also informed by close collaborations with colleagues in Australia, Europe and North America. This is exemplified by his recent books The New Psychology of Leadership: Identity, Influence and Power (Haslam, Reicher, \& Platow, 2011) and The Social Cure: Identity, Health and Well-being (Jetten, Haslam, \& Haslam, 2012).

Correspondence: Alex Haslam, School of Psychology, University of Queensland, St Lucia 4072, Australia, email:

A.Haslam@uq.edu.au 
really looked in the eye. Certainly, before this point, I had never been really impressed by any examples of leadership that I had studied, or shocked by any instances of stress, or terrified by any looming tyranny.

Vlad Glăveanu: One decade after the Prison Study how do you think its lessons regarding obedience, power, tyranny and rebellion have been integrated not only by the scientific literature on these topics but in the practical ways in which people and the media understand, portray and react to group behaviour especially when it involves aggression and resistance?

Alex Haslam: This is hard to assess, but I think it is clear that the study has had quite a lot of impact - and probably much more than we imagined it would have. Most obviously, this is because it has led people to question ideas that are deeply rooted in standard understandings of these phenomena (as associated with textbook accounts of Zimbardo and Milgram's work; see Smith \& Haslam, in press). Specifically, whatever else it does, the study reveals the limitations of the view that people conform naturally to roles and blindly follow orders. Going further, I think it is a bit harder for people to come to terms our argument that behaviour in both paradigms can be seen as a form of followership that is predicated upon both (a) leadership (on the part of the experimenters) and (b) identification with that leadership, as this involves quite a major rethink of the underlying psychology. However, here too, editors and reviewers have been far more receptive than we were expecting, and I think there are signs that our alternative analysis is starting to take hold. From the comments we get, I think this is because people find the ideas both refreshing and liberating - not only because they show that destructive behaviour is not an inevitable consequence of our psychological make up, but also because they point to the practical possibility of resistance.

Vlad Glăveanu: One of your most recent books is The New Psychology of Leadership: Identity, Influence and Power (NPoL; Haslam et al., 2011). This triad of identity, influence and power has been present in many forms in your work. How can it inform us about leadership and how is this 'new' psychology different from previous understandings of the phenomenon?

Alex Haslam: The long answer to this question is provided by the book itself, and I would make the point that this is a very good question that deserves a long answer. Briefly, though, the key point that we make is that leadership is a group process that centres on a partnership between leaders and followers - a partnership which becomes powerful (i.e., world-changing) to the extent that relevant parties perceive themselves to share a sense of social identity. In these terms, it is a shared sense of 'us' that gives meaning and direction to both leadership and followership and that not only aligns these two things but also makes them possible. There is a lot that is new about these ideas, but the most obvious thing is that they move beyond dominant models which see leadership as all revolving around the individual psychology or personal identity of the leader. In short, then, we see leadership (like much else in organizational psychology) as a 'we thing' not an 'I thing', and we also explain why this is the case and why it matters.

Vlad Glăveanu: What is your most current research focused on? How does this recent work continue, develop or create a shift from your previous interests?

Alex Haslam: I have just moved to the University of Queensland to start work on a project which will focus on two things. First, the contribution of social identity to the dynamics of health. We know from work that has been done over the course of the last decade that social identity processes feed into health outcomes in a range of important and interesting ways (e.g., by determining perceptions of symptoms, support, control, and isolation). Empirically, though, we have only just scratched the surface of these phenomena - especially as we haven't looked 
in much depth at how these interact with physiological and physical processes. Accordingly, these are issues I want to explore with colleagues like Jolanda Jetten and Catherine Haslam.

At the same time, I'm also keen to do more research into the social identity approach to organizational behaviour and, in particular, leadership (after Haslam, 2004). In part this will expand on work with Inma Advares-Yorno and Tom Postmes which has looked at the way in which creativity is structured by social identity and self-categorization processes - such that what people create and how it is received depends on how they understand themselves in relation to others (Adarves-Yorno, Postmes, \& Haslam, 2007; Adarves-Yorno, Haslam, \& Postmes, 2008). I also want to do more work with Steve Reicher on the idea that successful leadership involves identity impresarioship - the embedding of identities in the practices, rituals and habits of everyday group life (Reicher, Haslam, \& Hopkins, 2005). This is an idea we discuss a lot in our book, but which remains to be properly explored in psychological research.

Vlad Glăveanu: How do you see the relationship between theory and practice for a social and organisational psychologist as well as in your own work?

Alex Haslam: This is something I agonize quite a lot, because of all the questions I get asked when I give external talks (e.g., on leadership or stress), the most common is "This is great, and I believe everything you say; but how do I translate these ideas into practice?" And certainly "I don't know" isn't a very satisfactory answer. Accordingly, my colleagues and I have devoted quite a bit of energy to trying to develop answers, and to testing their efficacy. The clearest example of this is in the ASPIRe model (Haslam, Eggins, \& Reynolds, 2003) - which has now been supported in quite a wide range of settings, and in our specification of the three R's of leadership (reflect, represent, realize) at the end of NPoL. In all this, I follow Lewin's dictum that nothing is so practical as a good theory, but equally see practice (or more broadly 'what is going on in the world') as an essential testing ground for theory and as an agenda setter. Certainly, much of my work is stimulated by the impracticality of bad theory - and, unfortunately, there is a lot of this about.

Vlad Glăveanu: What would you say are some of the most interesting developments taking place today at the intersection between social and organisational psychology?

Alex Haslam: I think this has always been a very fertile niche in the discipline - as seen in work on topics like leadership, communication, negotiation, and diversity. As always, there is lots of interesting work being done on these and other topics at the moment, but one topic that I am currently fascinated by concerns the relationship between identity and space: on the one hand, the way that who we are determines how we create, manage, and respond to space, and, on the other, the way that the spaces we inhabit determine how we see ourselves and how we act. Some of our own work has looked at these issues in offices and care homes (Knight \& Haslam, 2010; Knight, Haslam, \& Haslam, 2010) - and the results have convinced me that there is much more to be done.

Vlad Glăveanu: Finally, what would be your advice for young and developing scholars (in social and organisational psychology but not only) on how to succeed in today's academic and professional world and make an impact through their psychological research?

Alex Haslam: I think there are two things that I would stress. First, collaborate. Apart from the fact that it's incredibly hard to make progress on your own, it's also a lot less fun. Second, choose your collaborators carefully, and when you find someone good to collaborate with, stick with them. The best collaborators force you to think straighter, 
work harder, and to aim higher. In my case this has involved working with people like John Turner, Steve Reicher, Craig McGarty, Naomi Ellemers, Jolanda Jetten, Tom Postmes, and Michelle Ryan. Great collaborators give you purpose, propulsion, and passion. It's a social identity thing.

Vlad Glăveanu: Thank you very much for sharing your thoughts with us.

Alex Haslam: Thank you for asking (and reading).

Vlad Glăveanu

EJOP Editor

\section{References}

Adarves-Yorno, I., Haslam, S. A., \& Postmes, T. (2008). And now for something completely different? The impact of group membership on perceptions of creativity. Social Influence, 3, 248-266. doi:10.1080/15534510802341124

Adarves-Yorno, I., Postmes, T., \& Haslam, S. A. (2007). Creative innovation or crazy irrelevance? The contribution of group norms and social identity to creative behavior. Journal of Experimental Social Psychology, 43, 410-416.

doi:10.1016/j.jesp.2006.02.013

Haslam, S. A. (2004). Psychology in organizations: The social identity approach (2nd ed). London: Sage.

Haslam, S. A., Eggins, R. A., \& Reynolds, K. J. (2003). The ASPIRe model: Actualizing Social and Personal Identity Resources to enhance organizational outcomes. Journal of Occupational and Organizational Psychology, 76, 83-113.

doi:10.1348/096317903321208907

Haslam, S. A., \& Reicher, S. D. (2006). Stressing the group: Social identity and the unfolding dynamics of responses to stress. The Journal of Applied Psychology, 91, 1037-1052. doi:10.1037/0021-9010.91.5.1037

Haslam, S. A., Reicher, S. D., \& Platow, M. J. (2011). The new psychology of leadership: Identity, influence and power. London: Psychology Press.

Jetten, J., Haslam, C., \& Haslam, S. A. (Eds.). (2012). The social cure: Identity, health and well-being. New York and Hove: Psychology Press.

Knight, C., \& Haslam, S. A. (2010). The relative merits of lean, enriched, and empowered offices: An experimental examination of the impact of workspace management strategies on well-being and productivity. Journal of Experimental Psychology. Applied, 16, 158-172. doi:10.1037/a0019292

Knight, C., Haslam, S. A., \& Haslam, C. (2010). In home or at home? How collective decision making in a new care facility enhances social interaction and wellbeing amongst older adults. Ageing and Society, 30, 1393-1418. doi:10.1017/S0144686X10000656

Reicher, S. D., \& Haslam, S. A. (2006). Rethinking the psychology of tyranny: The BBC prison study. The British Journal of Social Psychology, 45, 1-40. doi:10.1348/014466605X48998 
Reicher, S. D., Haslam, S. A., \& Hopkins, N. (2005). Social identity and the dynamics of leadership: Leaders and followers as collaborative agents in the transformation of social reality. The Leadership Quarterly, 16, 547-568. doi:10.1016/j.leaqua.2005.06.007

Smith, J. R., \& Haslam, S. A. (Eds.). (in press). Social psychology: Revisiting the classic studies. Thousand Oaks, CA: Sage. 